NBSIR 88-3732

\title{
Calculating Flows Through Vertical Vents in Zone Fire Models Under Conditions of Arbitrary Cross-Vent Pressure Difference
}

Leonard Y. Cooper

U.S. DEPARTMENT OF COMMERCE

National Bureau of Standards

National Engineering Laboratory

Center for Fire Research

Gaithersburg, MD 20899

May 1988
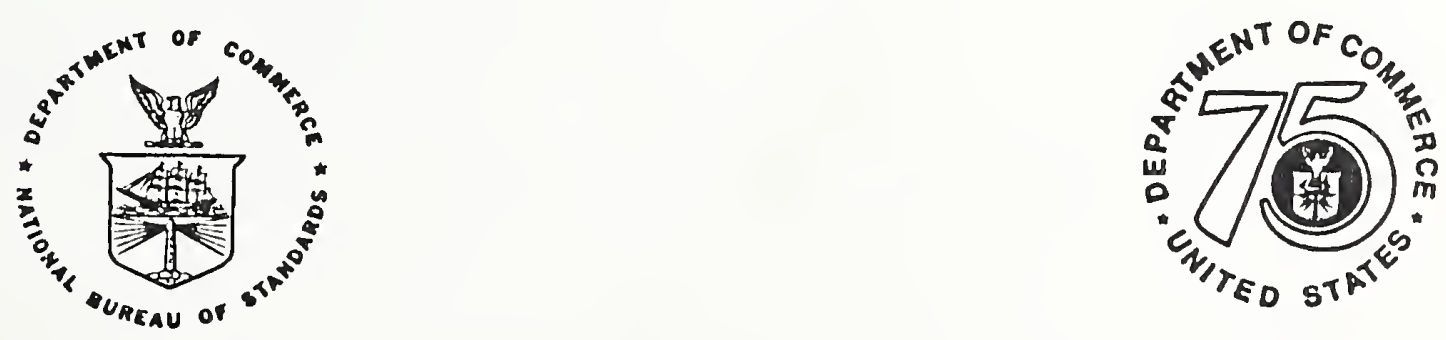

T6 Vero

U.S. DEPARTMENT OF COMMERCE NATIONAL BUREAU OF STANDARDS 


\section{。}

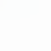


CALCULATING FLOWS THROUGH

VERTICAL VENTS IN ZONE FIRE MODELS

UNDER CONDITIONS OF ARBITRARY CROSS-VENT PRESSURE DIFFERENCE

Leonard Y. Cooper

U.S. DEPARTMENT OF COMMERCE

National Bureau of Standards

National Engineering Laboratory

Center for Fire Research

Gaithersburg, MD 20899

May 1988

U.S. DEPARTMENT OF COMMERCE, C. Wililam Verity, Secretary

NATIONAL BUREAU OF STANDARDS, Ernest Ambler, DIrector 


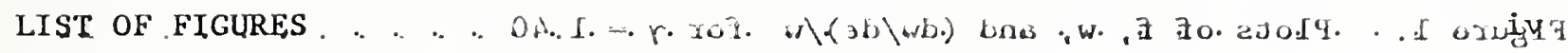
ABSTRACT . . . . . . . . . . . . . . . . . . . . . . . . . . . 1

1. Introduction... . . . . . . . . . . . . . . . . . . 2

2. The Two-Layer Description of a Compartment Fire Environment . . . . . 2

3. Cross-Vent Pressure Differences and the Slabs of the Vent Flow .... 3

4. The Mass Flow Rate Across the Vent at an Arbitrary Elevation. . . . . 4

5. The Total Slab Flow Rate for Relatively Small Cross-Vent Pressures . . 5

6. Total Slab Flow Rate for Arbitrarily Large Cross-Vent Pressures . . . 6

7. Properties of the Penetrating Flow . . . . . . . . . . . . . . . . . . 8

8. References... . . . . . . . . . . . . . . . . . 9

9. Nomenclature . . . . . . . . . . . . . . . . . 10 
LIST OF FIGURES

Page

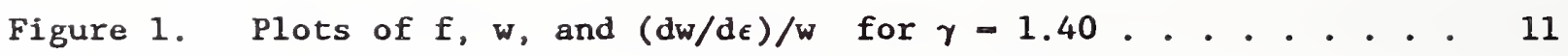




\title{
CALCULATING FLOWS THROUGH VERTICAL VENTS IN ZONE FIRE MODELS UNDER CONDITIONS OF ARBITRARY CROSS-VENT PRESSURE DIFFERENCE
}

\author{
Leonard Y. Cooper
}

\begin{abstract}
In typical compartment fire scenarios, ratios of cross-vent absolute pressures are very close to 1 . When such is the case, algorithms are available to predict the resulting cross-vent room-to-room flows. There are, however, important situations where this pressure condition does not prevail. For example, in fire scenarios involving relatively small penetrations in otherwise hermetically-sealed compartments of fire origin, cross-penetration pressure differences can be of the order of an atmosphere and pressure ratios, outside-to-inside, can be several tenths less than one. It is important for a versatile compartment fire model to have a capability of predicting vent flows for the entire range of possible cross-vent pressure conditions. This paper develops a unified analytic description for flows through uniform-width vertical vents connecting pairs of two-layer room fire environments under conditions of arbitrary cross-vent pressure difference. The analysis, which takes advantage of generally useful modeling approximations, leads to a concise result which is not significantly more complicated than the result for simple, low-pressure-difference cases.
\end{abstract}

Keywords: algorithms; building fires; compartment fires; computer models; computer programs; fire modeling; high-pressure; pressure differential; pressure effects; pressure vessels; vent flow; zone modeling. 


\section{Introduction}

Algorithms are available to predict cross-vent room-to-room flows in compartment fire environments (e.g., [1]-[4]). These are restricted generally to fire scenarios where ratios of cross-vent absolute pressures are close to 1. Although such a pressure condition is typical, there are important situations where it does not prevail, for example, in fire scenarios involving relatively small penetrations, holes or cracks, in otherwise hermeticallysealed compartments of fire origin. Reference here is to situations where penetrations are not so large and vent flows are not so vigorous that they disrupt fire-generated room environments to the point that otherwise-valid two-layer zone descriptions of such environments are inadequate.

To fix ideas, consider the following two-space fire scenario which involves the entire range of cross-vent pressure differences. Let two spaces be formed by a vertical partition which divides an hermetically-sealed compartment.

Assume initially that the separating partition is also hermetically-sealed and that the environment of both spaces are at standard temperature and pressure. Let a fire be initiated in one of the two spaces. As an elevated-temperature smoke layer grows in thickness below the ceiling, assume that the pressure in the fire space increases to a level above ambient of the order of one atmosphere (see, for example, the sample problem of [5]), while the environment in the adjacent space remains at its initial state. At this time assume further that a vertical crack develops and grows slowly in the partition, possibly as a result of a fracture in the wall, or of a failure of the pressure seal of a partition door hatch. When the crack first appears it is possible to estimate the flow across the crack, from the high-pressure space-of-fire-origin to the adjacent space, using compressible flow relations and without regard to relatively insignificant, hydrostatically-generated components of cross-crack pressure difference. Later, the cross-crack pressure differences will become small compared to the average absolute pressure of either of the two spaces. The hydrostatic contribution to these pressure differences will become significant and dominate eventually the flow. Indeed, one anticipates the development of one or more neutral planes, i.e., elevations of zero cross-crack pressure differential and flow, and corresponding flow direction reversals as one traverses the crack from top to bottom.

When conditions are such that zone-type modeling concepts are useful, it is important that a versatile compartment fire model have a capability of predicting vent flows for the entire range of possible cross-vent pressure conditions (e.g., to simulate the above fire scenario environment). This paper will develop a unified analytic description of flows through uniformwidth vertical vents connecting pairs of two-layer room fire environments under conditions of arbitrary cross-vent pressure difference.

\section{The Two-Layer Description of a Compartment Fire Environment}

In two-layer descriptions of compartment fire phenomena the environment in each room of a compartment is modeled generally as having an elevated. temperature upper gas layer and a relatively cool lower gas layer where each layer is assumed to be unfform in temperature, density, and composition. 
Define

$$
\delta=\rho g(y-\tilde{y}) / p(\tilde{y})
$$

where $y$ is an arbitrary elevation within a room layer of interest above a datum elevation, $\tilde{y}$ is an arbitrary fixed value of $y$ within the room, $\rho$ is the density in the layer, $g$ is the acceleration of gravity, and $p(y)$ is absolute pressure. In fire scenarios it is common for

$$
|\delta| \ll 1
$$

The above modeling assumptions and the approximation of Eq. (2) along with the momentum equation, i.e., hydrostatics, and the perfect gas law lead to

$$
\mathrm{p}(\mathrm{y})=\mathrm{p}(\tilde{\mathrm{y}})[1+0(\delta)] \approx \mathrm{p}(\tilde{y})
$$

and for this reason, the Eq. (3) approximation is adopted implicitly in twolayer zone models. It can also invoked explicitly to justify simplifications of pressure-work terms in the energy equation for rooms when such terms are non-negligible. For this latter application, however, the Eq. (3) approximation has not been used widely in practice.

To compute flow through vents, estimates of cross-vent pressure differences are required. But such differences are typically of the order of magnitude of the errors in the approximation of Eq. (3). When such is the case, Eq. (3) is usually too crude for the vent flow calculation and a detalled hydrostatic pressure calculation

$$
p_{i}(y)=p_{i}\left(\tilde{y}_{i}\right)-g \int \rho d y
$$

is usually needed, where in each room $1, y_{1}$ is a fixed elevation, say at the floor.

Eq. (4) together with the unfform layer density approximation leads to the result that in each room, $p(y)$ can be approximated by a linear function of elevation, where the slope of the pressure-elevation curve, determined by the density, changes only at the elevation of the interface separating the two layers.

\section{Cross-Vent Pressure Differences and the Slabs of the Vent Flow}

Consider an opening or vent in a common vertical wall segment joining two rooms, designated as rooms 1 and 2 , of a multi-room compartment. Flow through the vent will be driven at every elevation of the vent by the value of the pressure-difference function

$$
\Delta p_{12}(y)-p_{1}(y)-p_{2}(y)
$$

where $p_{1}$ and $p_{2}$ are the absolute pressure distributions in rooms 1 and 2 , respectively. The sign of $\Delta \mathrm{p}_{12}$ will determine the direction of the flow at any elevation, which will be from higher to lower pressure. 
In view of the description of the general intra-room pressure distribution, i.e., two piecewise-continuous linear functions of elevation, it can be shown, e.g., geometrically, that $\Delta \mathrm{p}_{12}$ will be described generally by three piecewisecontinuous linear functions (see, for example, Figures 3 and 5 of [1] and Figures 5 and 6 of [2]). Also, each of the three pieces can change sign, i.e., the flow can change direction, once in its elevation interval of applicability. The result of all this is that at any instant of time during a developing fire scenario the flow across a vertical vent will involve from one to six, stacked, horizontal slabs of cross-vent flow.

Number the flow slabs through a vent from the lowest ( $N=1$ ) to the highest (N NSLAB $\leq 6$ ), and designate the top and bottom elevation of a particular slab $N$ relative to the datum elevation as $y_{N}$ and $y_{N+1}$, respectively. Attention here is confined to the problem of estimating the rate of cross-vent flow in an arbitrary slab.

Between the $y_{N}$ and $y_{N+1}$ bounds of each slab the density and temperature of the flow's source and the direction of the flow are fixed. Also, throughout the thickness of a slab, $p_{1}, p_{2}$, and $\Delta p_{12}$ are each simple linear functions of elevation. $\Delta \mathrm{p}_{12} \mathrm{can}$ be zero at the bottom or top of a slab, and it can be. identically zero, i.e., a slab with zero cross-vent flow. But $\Delta \mathrm{p}_{12}$ cannot change signs in the slab.

We define $\Delta \rho$ and $\Delta \mathrm{p}$, and, with complete generality we number the two rooms so that the flow in the slab is from room 1 to room 2 .

$$
\begin{aligned}
& \Delta \rho \equiv \rho_{1}-\rho_{2} \\
& \Delta p(y)=\Delta p_{12}(y)=p_{1}(y)-p_{2}(y) \geq 0
\end{aligned}
$$

where $\rho_{1}$ and $\rho_{2}$ are the uniform densities in rooms 1 and 2 , respectively. Define $\Delta \mathrm{p}_{\mathrm{N}}, \mathrm{p}_{\mathrm{N}}$ and $\Delta \mathrm{p}_{\mathrm{N}+1}, \mathrm{p}_{\mathrm{N}+1}$ as the values of $\Delta \mathrm{p}, \mathrm{p}_{1}$, at $\mathrm{y}-\mathrm{y}_{\mathrm{N}}$ and $\mathrm{y}_{\mathrm{N}+1}$, respectively. Then Eq. (4) leads to

$$
\begin{aligned}
& p_{1}(y)=p_{N}-\rho_{1} g\left(y-y_{N}\right) \\
& \Delta p(y)=\Delta p_{N}-\Delta \rho g\left(y-y_{N}\right)
\end{aligned}
$$

or

$$
\begin{aligned}
& p_{1}(y)=p_{N+1}\left(y-y_{N}\right) /\left(y_{N+1}-y_{N}\right)-p_{N}\left(y-y_{N+1}\right) /\left(y_{N+1}-y_{N}\right) \\
& \Delta p(y)=\Delta p_{N+1}\left(y-y_{N}\right) /\left(y_{N+1}-y_{N}\right)-\Delta p_{N}\left(y-y_{N+1}\right) /\left(y_{N+1}-y_{N}\right)
\end{aligned}
$$

through the slab.

4. The Mass Flow Rate Across the Vent at an Arbitrary Elevation

Adopting the traditional one-dimensional approximation and assuming isentropic flow, the mass flow rate of a compressible gas across a vent or nozzle per unit area, $\mathrm{m}^{\prime \prime}(\mathrm{y})$, is given by [6] 


$$
m^{\prime \prime}(y)=C\left(2 \rho_{1} \Delta p\right)^{1 / 2} w(x)=C\left(p_{1} \rho_{1}\right)^{1 / 2} f(x)
$$

where

$$
\begin{aligned}
& w(x)=f(x) /[2(1-x)]^{1 / 2} \\
& f(x)= \begin{cases}\left([2 \gamma /(\gamma-1)] x^{2 / \gamma}\left[1-x^{(\gamma-1) / \gamma}\right]\right)^{1 / 2} & \text { for } x \geq[2 /(\gamma+1)]^{\gamma /(\gamma-1)} \\
(\gamma[2 /(\gamma+1)](\gamma+1) /(\gamma-1))^{1 / 2} & \text { for } x \leq[2 /(\gamma+1)]^{\gamma /(\gamma-1)}\end{cases} \\
& \mathrm{x}=\mathrm{p}_{2} / \mathrm{p}_{1}=1-\Delta \mathrm{p} / \mathrm{p}_{1}
\end{aligned}
$$

and where $\gamma$ is the ratio of specific heats and $C$ is a flow coefficient which depends generally on Reynolds number and $x$. For perfectly isentropic flow, $C$ $=1$. For well-designed nozzles, $C$ can be very close to 1 , of the order of 0.99, when flows have "pipe" Reynolds numbers of $10^{6}$ or more ([6], p.99). For sharp-edged orifices, $C=C(x)$ and is approximately linear with $x$, ranging from 0.6 at $x=1$ to 0.85 at $x=0$ (see Figure 4.17, p.100 of [6]). For orifice-like openings typical of vents in compartment fires $C \approx 0.68$ for $\mathrm{x}$ close to 1 [1]. All these results suggest that it is reasonable to approximate $C(x)$ for vents, holes or slits in compartment fires by

$$
C(x)=0.68 x+0.85(1-x)=0.85-0.17 x ; 0 \leq x \leq 1
$$

unless a more precise description of $C$ is known for some particular vent configuration of interest.

For air, $\gamma \approx 1.40$ and the change from the first to the second of Eq. (13) occurs at the choked flow condition

$$
\mathrm{x}=[2 /(\gamma+1)]^{\gamma /(\gamma-1)} \approx 0.528
$$

$f(x)$ and $w(x)$ are plotted in Figure 1 for $y-1.40$.

5. The Total Slab Flow Rate for Relatively Small Cross-Vent Pressures Define

$$
\epsilon(\mathrm{y})=\Delta \mathrm{p} / \mathrm{p}_{1}=1-\mathrm{x} \geq 0
$$

and note from Eqs. (11) and (16) that for air and for a specified $p_{1}, \rho_{1}$ condition, reductions of $p_{2}$ do not change $\mathrm{m}^{\prime \prime}(y)$ once $\epsilon$ exceeds the choked value 0.472 .

In most common compartment fire scenarios

$$
\left|\Delta \mathrm{p} / \mathrm{p}_{1}\right|=|\epsilon(\mathrm{y})| \ll 1
$$

through the depth of any flow slab. From Eqs. (12)-(14) a small-t expansion of $w$ leads to 


$$
\lim _{x \rightarrow 1} w(x)=\lim _{\epsilon \rightarrow 0} w(1-\epsilon)=1-[3 /(4-\gamma)] \epsilon(y)+O\left(\epsilon^{2}\right)
$$

From Eq. (11) it therefore follows that

$$
\lim _{\epsilon \rightarrow 0} \mathrm{~m}^{\prime \prime}(\mathrm{y})=C\left(2 \rho_{1} \Delta \mathrm{p}\right)^{1 / 2}\left(1-[3 /(4 \gamma)] \epsilon(\mathrm{y})+0\left(\epsilon^{2}\right)\right\}
$$

Approximating the above by the leading term in the expansion results in the commonly useful expression for the total mass flow rate, $m$, of the slab through a vent of uniform width, $b$,

$$
\lim _{\max |\epsilon| \rightarrow 0}=b C\left(2 \rho_{1}\right)^{1 / 2} \int(\Delta p)^{1 / 2} d y
$$

where $\max |\epsilon|$ is the maximum value of $\epsilon$ in the slab and the integral is over the thickness of the slab.

Using Eq. (10), the integral of Eq. (21) can be evaluated to yfeld [1]

$$
\begin{array}{r}
\lim _{\max |\epsilon| \rightarrow 0}=\operatorname{bC}\left[\left(8 \rho_{1}\right)^{1 / 2} / 3\right]\left(y_{N+1}-y_{N}\right)\left[\left(\left|\Delta \mathrm{p}_{N}\right|+\left|\Delta \mathrm{p}_{N} \Delta \mathrm{p}_{N+1}\right|^{1 / 2}+\left|\Delta \mathrm{p}_{N+1}\right|\right) /\right. \\
\left.\left(\left|\Delta \mathrm{p}_{N}\right|^{1 / 2}+\left|\Delta \mathrm{p}_{N+1}\right|^{1 / 2}\right)\right]
\end{array}
$$

which is equivalent completely to mass flow rate calculations in [2]-[4]. Use of Eq. (22) requires $\max |\epsilon|$ to be small. Since $\Delta p$ and $p_{1}$ are both $l$ inear and monotonic in $y$, then $\epsilon$ is also monotonic in $y$. Thus, the utility of Eq. (22) can be established by showing that

$$
\max \left|\Delta \mathrm{p} / \mathrm{p}_{1}\right|=\max |\epsilon(\mathrm{y})|=\max \left|\epsilon_{\mathrm{N}}, \epsilon_{\mathrm{N}+1}\right|-\max \left|\Delta \mathrm{p}_{\mathrm{N}} / \mathrm{p}_{\mathrm{N}}, \Delta \mathrm{p}_{\mathrm{N}+1} / \mathrm{p}_{\mathrm{N}+1}\right| \ll 1
$$

where $\epsilon_{\mathbb{N}}$ and $\epsilon_{N+1}$, the values of $\epsilon$ at $y_{N}$ and $y_{N+1}$, respectively, can be computed with the use of Eqs. (9) and (10).

\section{Total Slab Flow Rate for Arbitrarily Large Cross-Vent Pressures}

There are important situations where $\epsilon$ is not small, for example, in fire scenarios involving relatively small penetrations connecting otherwise hermetically sealed compartment spaces. "In such cases the basic two-layer zone model may still be useful and the approximations of Eqs. (2) and (3) will usually still be valid. In general, whether or not $\epsilon$ is small, Eq. (1) and the definition of $\epsilon$ lead to

$$
\mathrm{x}(\mathrm{y})=1-\epsilon=\mathrm{p}_{2} / \mathrm{p}_{1}=\mathrm{x}(\overline{\mathrm{y}})[1+O(\bar{\delta})]-(1-\bar{\epsilon})[1+O(\bar{\delta})]-1 \cdot \bar{\epsilon}+0(\bar{\delta})
$$

where

$$
\begin{aligned}
& \bar{\delta}=\max \left(\delta_{1}, \delta_{2}\right) ; \delta_{1} \ll 1 ; \delta_{2} \ll 1 \\
& \bar{\epsilon}=\epsilon(\bar{y})
\end{aligned}
$$


and where $\delta_{1}$ and $\delta_{2}$ are values of the $\delta$ of Eq. (1) for rooms 1 and 2, respectively, $y$ is confined to the range of elevations in the vent slab of interest, and $\tilde{y}$, also confined to the slab, is the same flxed elevation for both rooms 1 and 2 .

From Eq. (24) it follows that

$$
\epsilon=\bar{\epsilon}+O(\bar{\delta})
$$

uniformly through the thickness of a slab. Noting that $w$ is an analytic function of $\epsilon$ near the real $\epsilon$ axis in the range

$$
0<\epsilon<1-[2 /(\gamma+1)]^{\gamma /(\gamma-1)}
$$

$\tilde{\epsilon}$ is assumed to be in this range and $w$ is expanded at $\epsilon-\bar{\epsilon}$ within the small region $|\epsilon-\bar{\epsilon}|=O(\bar{\delta})$

$$
\lim _{\bar{\delta} \rightarrow 0} w=\left.w\right|_{\epsilon=\bar{\epsilon}}+d w / d \epsilon \mid \underset{\epsilon=\bar{\epsilon}}{\infty} O(\bar{\delta})
$$

Since $\epsilon$ in any slab is monotonically increasing or decreasing with $y$ we can insure that $\dot{\epsilon}>0$ by choosing $\dot{y}$ to be at the mid-elevation of the slab of , interest. Thus, using Eqs. (9), (10), and (17)

$$
\tilde{\epsilon} \equiv \epsilon\left(\mathrm{y}=\tilde{\mathrm{y}}=\left[\mathrm{y}_{\mathrm{N}}+\mathrm{y}_{\mathrm{N}+1}\right] / 2\right) \equiv 1-\tilde{\mathrm{x}}=\left(\Delta \mathrm{p}_{\mathrm{N}}+\Delta \mathrm{p}_{\mathrm{N}+1}\right) /\left(\mathrm{p}_{\mathrm{N}}+\mathrm{p}_{\mathrm{N}+1}\right)
$$

Since $w$ is never zero

$$
\lim _{\bar{\delta} \rightarrow 0} w=\left.w\right|_{\epsilon=\tilde{\epsilon}}\left\{1+\left.[(\mathrm{dw} / \mathrm{d} \epsilon) / w]\right|_{\epsilon=0} O(\bar{\epsilon})\right\}
$$

$(\mathrm{dw} / \mathrm{d} \epsilon) / \mathrm{w}$ was computed from Eqs. (12) $-(14)$ and is plotted in Figure 1 . As can be seen, the absolute value of this term never exceeds 1.04 . It is concluded, therefore, that for arbitrary $\epsilon$ the estimate

$$
w=w||_{\epsilon=\bar{\epsilon}}[1+O(\bar{\delta})] \approx w \mid \underset{\epsilon=\bar{\epsilon}}{=} w(x-\tilde{x}=1-\bar{\epsilon})=\tilde{w}
$$

is valid uniformly in the entire slab. Also, it is evident from the above that Eq. (31) can be extended to situations where $\bar{\epsilon}$ exceeds the Eq. (27) range.

Just as the above analysis of $w$ lead to Eq. (31), a similar analysis of C would lead to

$$
C=\left.C\right|_{\epsilon=\bar{\epsilon}}[1+O(\bar{\delta})] \approx C \mid=C(x-\tilde{x}-1-\bar{\epsilon})=C
$$

Eqs. (31) and (32) are now used in Eq. (11) which is then integrated over the slab to obtain

$$
m=b C \tilde{w}\left(2 \rho_{1}\right)^{1 / 2}\left[\int(\Delta p)^{1 / 2} d y\right]
$$


As was done earlier below Eq. (21), the above integral is evaluated to yieldthe final unified result for $\mathrm{m}$, valid for arbitrary $\bar{\epsilon}$.

$$
\begin{array}{r}
m=\mathrm{bC \tilde {w }}\left[\left(8 \rho_{1}\right)^{1 / 2} / 3\right]\left(\mathrm{y}_{\mathrm{N}+1}-\mathrm{y}_{\mathrm{N}}\right)\left[\left(\left|\Delta \mathrm{p}_{\mathrm{N}}\right|+\left|\Delta \mathrm{p}_{\mathrm{N}} \Delta \mathrm{p}_{\mathrm{N}+1}\right|^{1 / 2}+\left|\Delta \mathrm{p}_{\mathrm{N}+1}\right|\right) /\right. \\
\left.\quad\left(\left|\Delta \mathrm{p}_{\mathrm{N}}\right|^{1 / 2}+\left|\Delta \mathrm{p}_{N+1}\right|^{1 / 2}\right)\right]
\end{array}
$$

where $C$ and $\bar{w}$ are defined in Eqs. (31) and (32) and can be computed with the use of Eqs. (12)-(15) and (29). To compute m numerically from Eq. (34), the limit of Eq. (19) in small $\tilde{\epsilon}$ situations is useful in the evaluation of $\bar{w}$ from Eqs. (12)-(14).

It is noteworthy that when $\bar{\epsilon}-1-\tilde{x}-0,1 . e ., \tau-C_{I N C O M P R E S S I B L E}$ and $\tilde{w}-1$, Eq. (34) is identical to the small-cross-vent-pressure-difference flow equation of Eq. (22). Thus, a simple interpertation of Eq. (34) is that when compressibility effects are arbitrarily strong or weak, the compartment firegenerated flow rate of a slab of flow, originating from a uniform stagnation source and passing through a constant-width vertical vent, can be computed by ignoring elevation-related differences of compressibility in the slab and by using the characteristic mass flux for compressible nozzle/orifice flow which corresponds to the mid-slab cross-vent pressure difference.

\section{Properties of the Penetrating Flow}

In order to use Eq. (34) in any particular room fire model it is necessary to know the properties of the penetrating jet as it enters room 2 . With such information in hand it would then be possible to invoke the model's adopted rule for dividing and depositing this incoming flow into the room's upper and lower layer. The desired result is obtained by observing that the flow across the penetration is basically of constant total enthalpy. Thus, assuming deceleration to negligible velocity prior to mixing in the receiving room, the temperature $\mathrm{T}_{2}$ will be identical to $\mathrm{T}_{1}$, the stagnation temperature in the originating room.

$$
\mathrm{T}_{2}-\mathrm{T}_{1}
$$

Using this result, the density $\rho_{2}$ can be obtained from the perfect gas law.

$$
\rho_{2}=\rho_{1}\left(\mathrm{p}_{2} / \mathrm{p}_{1}\right)=\rho_{1} \mathrm{x}
$$

For the most common fire scenarios where cross-vent pressure ratios, $x$, are close to 1, the above leads to the correct result that the properties of the penetrating flow are identical to the properties of the jet's source ambient environment in room 1 . 
8. References

[1] Emmons, H.W., The Flow of Gases Through Vents, Home Fire Project Technical Report 75, Division of Applied Sciences, Harvard University, March $16,1987$.

[2] Zukoski, E.E., and Kubota, T., Two-Layer Modeling of Smoke Movement in Building Fires, Fire and Materials, Vol. 4, No. 1, 1980.

[3] Tanaka, T., A Model of Multiroom Fire Spread, NBSIR 83-2718, National Bureau of Standards, Gaithersburg, MD, 1983.

[4] Jones, W.W., and Bodart, X., Buoyancy Driven Flow as the Forcing Function of Smoke Transport Models, NBSIR 86-3329, National Bureau of Standards, Gaithersburg, MD, 1986.

[5] Cooper, L.Y., and Forney, G.P., Fire in a Room with a Hole: A Prototype Application of the Consolidated Compartment Fire Model (CCFM) Computer Code, Proceedings of the Combined 1987 Fall Technical Meeting of the Eastern Section of the Combustion Institute and Annual CFR Research Conference, National Bureau of Standards, Gaithersburg, MD, 1987.

[6] Shapiro, A.H., The Dynamics and Thermodynamics of Compressible Fluid Flow: Volume 1, Roland Press, 1953. 


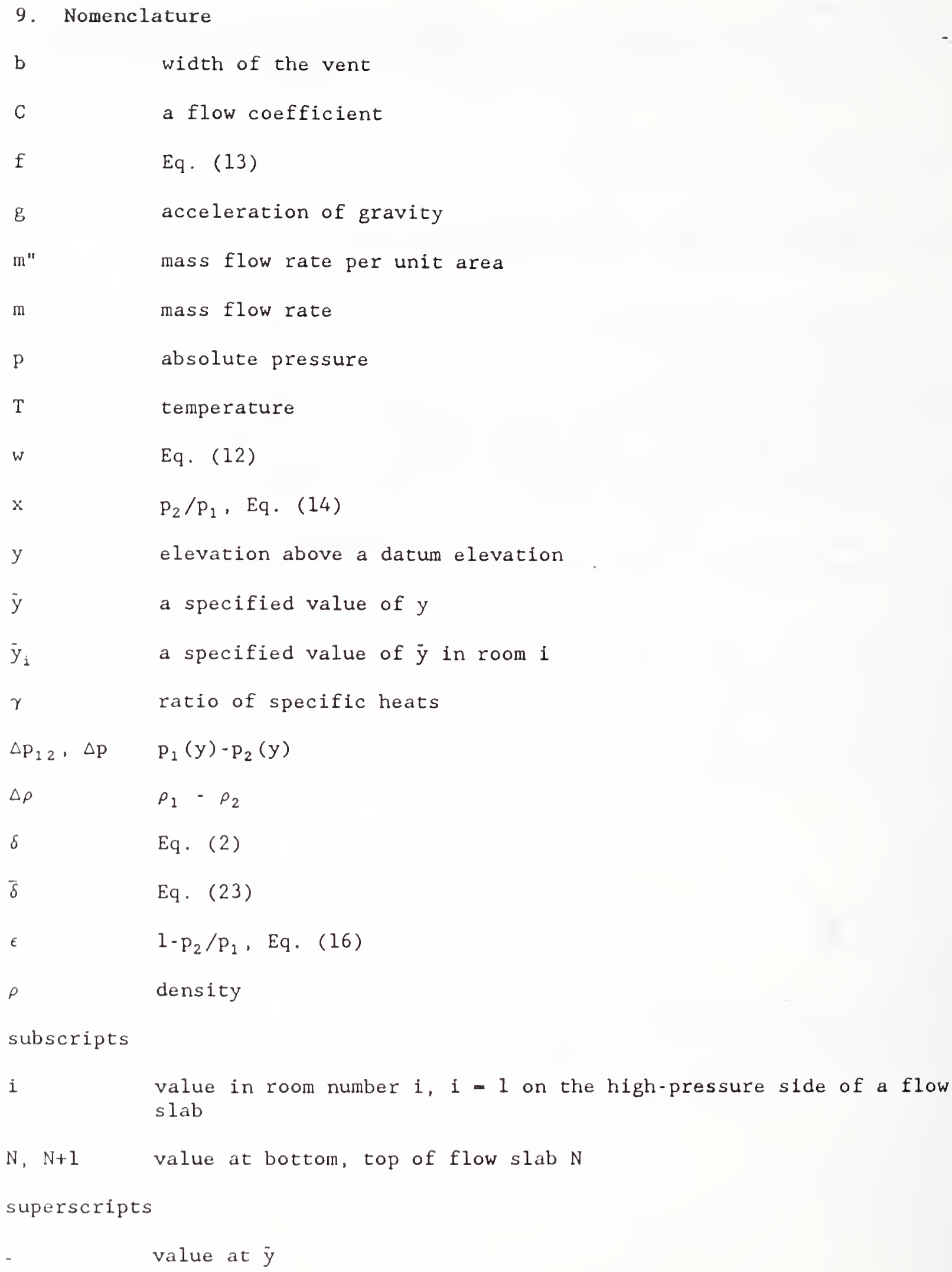




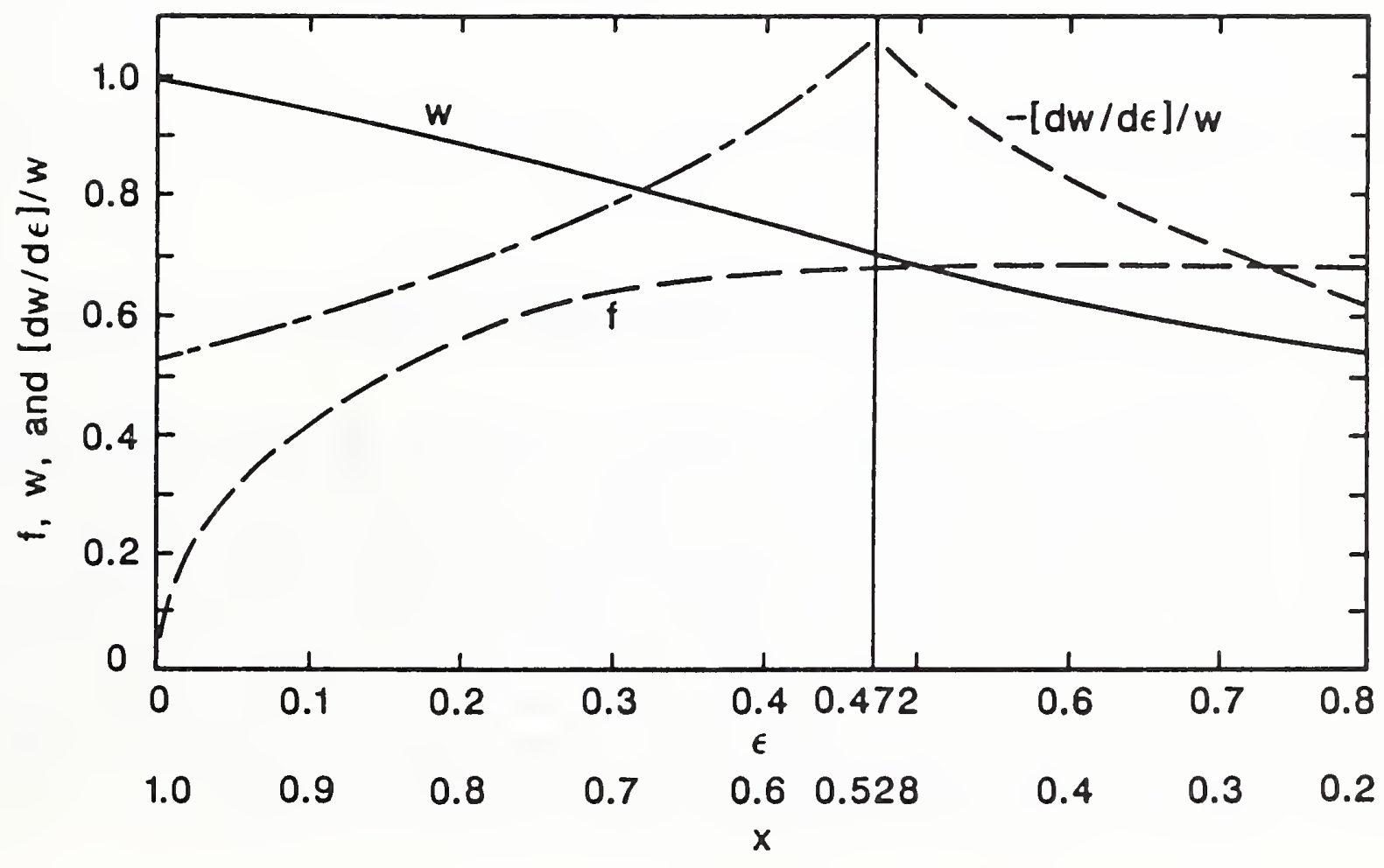

Figure 1. Plots of $f, w$, and $(d w / d \epsilon) / w$ for $\gamma=1.40$ 
BIBLIOGRAPHIC DATA

SHEET (See instructions)

4. TITLE AND SUBTITLE

Calculating Flows Through Vertical Vents in Zone Fire Models Under Conditions of Arbitrary Cross-Vent Pressure Difference

\section{AUTHOR(S)}

Leonard Y. Cooper

6. PERFORMING ORGANIZATION (If joint or other thon NBS, see Insiructions)

7. ContracV Grant No.

NATIONAL BUREAU OF STANDARDS

U.S. DEPARTMENT OF COMMERCE

8. Type of Report \& Perlod Covered GAITHERSBURG, MD 20899

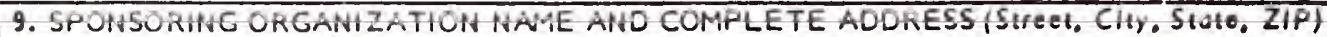

10. SUPPLEMENTARY NOTES

[] Document describes a computer program; SF-185, FIPS Software Summary; Is attached.

11. ABSTRACT (A 200-word or less foceuol summory of most s/gnificone Information. If document includes a slgnilfcone bibliogrophy or literoture survey, mention it here)

In typical compartment fire scenarios, ratios of cross-vent absolute pressures are close to 1 . When such is the case, algorithms are avallable to predict the resulting cross-vent room-to-room flows. There are, however, 1mportant situations where this pressure condition does not prevall, for example, in fire scenarlos involving relatively small penetrations in otherwise hermetically-sealed compartments of fire origin. It is important for a versatile compartment fire model have a capability of predicting vent flows for the entire range of possible cross-vent pressure conditions. This paper develops a unified analytic description for flows through vertical vents between pairs of two-layer room fire environments under conditions of arbitrary crossvent pressure difference. The analysis, which takes advantage of generally useful modeling approximations, leads to a conolse result which is not significantly more complicated than the result for simple, low-pressure-difference cases.

12. KEY WORDS (Six to iwelve entries: alphabetical order: capltallze only proper names; and soparote key words by semlcolons) algorithms; building fires; compartment fires; computer models; computer programs; fire modeling; high-pressure; pressure differentlal; pressure effects; pressure vessels; vent flow; zone modeling

13. AVAILABILITY

[X] Unlimited

$\square$ For Official Distribution. Do Not Release to NTIS

TO Order From Superintendent of Documents, U.S. Government Printing Offico, Washlngton, D.C. 20402.

[S] Order From National Technical Information Service (NTIS), Springfleld, VA. 2216I

14. NO. OF PRINTED PAGES 16

15. Prlce 

